\title{
LINGUISTICA XVI-XXX
}

\section{TABLE CHRONOLOGIQUE}

\author{
XVI, 1976
}

1. Bojan ČOP: Méditerranéen et Indo-Ouralien - Mediteranski substrat in indouralska teorija; 3-33

2. Siegfried HEUSINGER: Zur Ausrahmung und ihrer Funktion -Izpostavljanje stavčnega elementa in njegova funkcija; 35-45

3. Josip JERNEJ: Reggenza e accordo - Rekcija i kongruencija; 47-53

4. Silvin KOŠAK: The Hittite nuntarrijashas - Festival (CTH 626) - Hetitski "Festival hitrosti" (CTH 626); 55-64

5. Rado LENČEK: On the use of the gerund in $-\check{c}$ in the Slovene dialects contiguous with Friulian - Raba gerundija sedanjega časa v slovenskih govorih v kontaktu s furlanšcino; 65-79

6. Milena MILOJEVIĆ-SHEPPARD: Pronouns and the problem of reference in transformational grammar - Zaimki in problem reference $v$ transformacijski slovnici; 81-96

7. Janez OREŠNIK: Inflection of Modern Icelandic Nouns, Adjectives and Adverbs - Fleksija novoislandskih samostalnikov, pridevnikov in prislovov; 97-118

8. Giovan Battista PELLEGRINI: Continuatori balcanico-danubiani del veneto "balota" - Beneško balota: izposojenka v balkansko-podonavski sferi; 119-123

9. Magnús PETURSSON: Linguistiche Phonetik - Lingvistička fonetika; 125-136

10. Vladimir POGAČNIK: Les unités sémantiques de l'anaphorique français en dans la représentation elliptique - Pomenske enote francoske anafore en v eliptični substituciji; 137-152

11. Milica POPOVIĆ: Problematika saopštavanja nekih književnih pojmova u italijanskim enciklopedijskim rečnicima - Problematica di comunicazioni letterarie nei piccoli vocabolari enciclopedici; 153-159

12. William R. SCHMALSTIEG: The Slavic Genitive Singular as the Subject of Participles in -no- and -to - Slovanski rodilnik ednine kot osebek deležnikov na -noin - to-161-163

13. Alenka ŠIVIC-DULAR: Južnoslovansko siromah - Südslavisches siromah;165-169

14. Gordana VITOROVIĆ: Quinze ans de "Linguistica" - Petnajst let "Linguisticae"; 171-198 
15. William R. SCHMALSTIEG: A note on Hittite $d a-a b$-hi - Opazka o hetitsko da$a b-h i ; 3-8$

16. Bojan ČOP: Zur Flexion des hethitischen Verbalsubstantivs auf -uar- - K sklanjatvi hetitskega glagolnika na -uar-; 9-21

17. Alemko GLUHAK: Etruscan mqlena "mirror" - Etrurski malena "zrcalo"; 23-24

18. Alemko GLUHAK: Etruscan numerals - Etrurski brojevi; 25-32

19. N.I. TOLSTOJ: O neposledovatel'nosti pervoj palatalizacii slovjanskih zadnenebnyh soglasnyh - K vprašanju o prvi palatalizaciji slovanskih mehkonebnikov; 33-47

20. William W. DERBYSHIRE: Some Comments on the Origin of Homonymy in the Slavic Languages - K izvoru homonimije v slovanskih jezikih; 49-55

21. Siegfried HEUSINGER: Die Ausbildung von Wertbedeutungen im Schuljugendalter - O razvoju vrednosti pomenov pri mladini v solski starosti; 57-71

22. Mágnús PÉTURSSON: La quantité en islandais moderne: un fait régional - Kvantiteta v moderni islandక̌cini: regionalni pojav; 73-89

23. Janez OREŠNIK: Inflection of modern Icelandic verbs and pronouns - Fleksija novoislandskih glagolov in zaimkov; 91-122

24. Milan GROŠELJ: De nonnullis vocibus in Lexico latinitatis medii aevi Iugoslaviae (A-P) obviis - O nekaterih besedah v Lexicon latinitatis medii aevi Iugoslaviae (A-P); 123-124

25. Franco CREVATIN: Parole istriane - Nekaj istrskih besed; $125-130$

26. Momcilo D. SAVIĆ et Stefan POPA; Quelques aspects du bilinguisme dans la zone linguistique roumaino-serbo-croate - Unele aspecte ale bilinvismului în zone limbilor româna si sîrbocroata; 131-141

27. Mitja SKUBIC: Sur les valeurs des temps du passé dans les langues romanes - $\quad 0$ vrednosti glagolskih oblik za preteklost v romanskih jezikih; 143-150

$$
\begin{aligned}
& \text { Poroxila, ocene in zapisi - Comptes rendus, } \\
& \text { récensions, notes }
\end{aligned}
$$

28. Pavao TEKAVČIĆ: Due recenti contributi statunitensi alla linguistica romanza e latina; 161-206 


\section{XVIII, 1978}

29. Rado L. LENČEK: Jan Baudouin de Courtenay's concept of mixed languages Baudouinov koncept "mešanja" jezikov in dialektov; 3-28

30. Manlio CORTELAZZO: Un presunto slavismo nell'opera di Pietro Aretino Domneven slavizem v delih Pietra Aretina; 29-30

31. Vilko NOVAK: O grafiki prve prekmurske knjige - Die Graphik des ersten Buches von Prekmurje; 31-45

32. Alemko GLUHAK: Slovenske etimologije - Slavic etymologies; 47-50

$$
* * *
$$

33. Franco CREVATIN: Vedica minora; $51-56$

34. Varja CVETKO: Zur problematik der altindischen Kausativa mit langem Vokalismus - Problem staroindijskih kavzativov z dolgim vokalizmom; 57-98

35. Silvin KOŠAK: The inventory of Mannini (CTH 5O4) - Inventar Manninijevih dragocenosti; 99-123

36. Magnús PETURSSON: La quantité en islandais moderne - Kvantiteta v moderni islandక̌cini; 125-140

37. Janez OREŠNIK: Modern Icelandic preaspiration from the phonological point of view - Novoislandska preaspiracija s fonološkega vidika; 141-166

38. Siegfried HEUSINGER: Thesen zur Sprachentwicklung im Schuljugendalter Teze o jezikovnem razvoju mladine v solski starosti; $167-190$

39. Breda CIGOJ-LEBEN: Le style d'André Gide dans "Le Retour de l' Enfant prodigue" - Stil Andreja Gida v "Povratku izgubljenega sina"; 191-216

40. Darja ŽORGA-GLOBEVNIK: Essai d'analyse sémantique des modalités verbales prédicatives dans un texte de G. Flaubert - Poskus semantične analize modalnosti pri glagolu v delu Gustava Flauberta; 217-236

41. Pavao TEKAVČIĆ: Sintassi e semantica nella coordinazione avversativa e sostituiva - Sintaksa in semantika protivnega in nadomeščevalnega priredja; 237-258

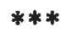

Poročila, ocene in zapisi -

Comptes rendus, récensions, notes

42. Žarko MULJAČIĆ: Putovanje Alberta Fortisa u Ljubljanu - Sul viaggio di Alberto Fortis a Lubiana; 259-260 
43. Mágnus PÉTURSSON: Isländich. Eine Ubersicht über die moderne isländiche Sprache mit einem kurzen Abriss der Geschichte und Literatur Islands. Hamburg: Helmut Buske Verlag. 1978. Pp XII, 220 + map. (Janez Orešnik); 261-264

44. Gian Battista PELLEGRINI: Studi di dialettologia e filologia veneta. Pacini Editore, Pisa 1977. 546 pag. (Mitja Skubic); 265-268

$$
\text { XIX, } 1979
$$

45. Milan GROŠELJ (1902-1979)

46. Erika MIHEVC-GABROVEC: Üeber Prof. Milan Grošeljs wissenschaftliches Werk - O znanstvenem delu prof. Milana Groslja; 7-24

47. Kajetan GANTAR: Profesor Milan Grošelj in literarna zgodovina - Professor Milan Groselj und die Literaturgeschichte; 25-37

48. Martin BENEDIK: Bibliografija prof. Milana Groslja; 39-43

49. Boleslav S. POVŠIČ: Cicero's De legibus and Martin Luther King, Jr.'s Stride Toward Freedom - Ciceronov spis $O$ zakonih (De legibus) in Kingova Pot $k$ svobodi (Stride Toward Freedom)

50. M.D. PETRUŠEVVSKI: Hom. hypódra; str. 57-63

51. Tine KURENT: The Vitruvian symmetria means "modular sizes" - Vitruvijeva symmetria pomeni "modularne mere"; 65-78

52. Mario DORIA: Toponomastica longobarda a Trieste e sul Carso - Krajevna imena langobardskega izvora v Trstu in na Krasu; 79-97

53. Anton GRAD: Starejక̌i grecizmi v slovenščini (I) - Anciens grécismes en slovène (I); $99-118$

54. Carlo Alberto MASTRELLI: Etimologia del contesto - latinismi ecclesiastici: ital. visibilio, strabiliare e trasecolare - Etimologija sobesedila - cerkveni latinizmi: ital. visibilio, strabiliare in trasecolare; 119-132

55. Franco CREVATIN: Pagine di storia linguistica istriana (VII) - Iz istrske jezikovne zgodovine (VII); 133-141

56. Pavao TEKAVČIĆ: La morfosintassi nell'individualità dell'istroromanzo - Uloga morfosintakse $u$ individualnosti istroromanskih govora; 143-156

57. Richard SIRBU: L'antonymie comme manifestation des relations de système dans le lexique - Antonimija kot izraz sistemskih odnosov v besedišcu; 157-169

58. Momčilo D. SAVIĆ: L'uso dei tempi passati nei quotidiani pubblicati nelle lingue romanze con particolare riguardo all'italiano - Upotreba prošlih vremena u dnevnoj stampi na romanskim jezicima s posebnim osvrtom na italijanski; 171-197

59. Željka RANČIGAJ - Pavao TEKAVČIĆ: Tanto iniziale di frase e parole affini. Considerazioni semantico-sintattiche - $\mathrm{O}$ semantici i sintaksi talijanskog tanto (na početku rečenice) i drugih analognih riječi; 199-222 
60. Darja GLOBEVNIK: Syntaxe et/ou sémantique à propos du subjonctif français Sintaksa in/ali semantika glede na francoski konjunktiv; 223-242

61. Mitja SKUBIC: Oracions subordinades amb infinitiu en el català antic - Odvisniki $\mathrm{z}$ infinitivom $\mathrm{v}$ stari katalonščini; 243-255

62. Kenneth SHIELDS: The Origin of the IE Endingless Locative - Izvor indoevropskega brezkončniškega mestnika; 257-274

63. Varja CVETKO: Zur Frage der Deutung der Archaismen und Innovationen anhand einiger arischbaltoslawischer Beispiele - $\mathrm{K}$ vprašanju pojmovanja arhaizmov in inovacij v luči nekaj indoiransko-baltoslovanskih primerov; 275-285

\section{$\mathrm{XX}, 1980$}

64. Milivoj SIRONIĆ: Semonidova vizija života - Die Lebensvision des Semonides; 3-8

65. Marjeta ŠAŠEL-KOS: Fragment einer widersprüchlich interpretierten griechischen Inschrift aus Poetovio - Fragment spornega grškega napisa iz Ptuja; 11-20

66. Primož SIMONITI: Auf den Spuren einer Aristophanes-Handschrift (cod. Tub. gr. Mb 32) - Po sledeh rokopisa z Aristofanovo komedijo Plutos; 21-33

67. Silvin KOŠAK: The Hittites and the Greeks - Hetiti in Grki; 35-48

68. Peter PETRU: Upodobitev pisarja na reliefu iz Ajdovskega gradca nad Vranjem pri Sevnici - Die Abbildung eines Schreibers auf dem Relief aus Ajdovski gradec über Vranje bei Sevnica; 49-57

69. Jaro ŠAŠEL: AQUO, AQUONIS, m., personifikacija in imensko izhodišč za potok Voglajna - AQUO, AQUONIS, m., Personifizierung und Namensursprung für den Voglajna-Bach; 61-66

70. Ljiljana CREPAJAC: Razmatranja o dva indoevropska leksemska minimuma Betrachtungen über zwei indoeuropäische Wurzeln; 67-76

71. Giovan Battista PELLEGRINI: Nomi di piante nell'area dolomitica e friulana (VI) - Imena rastlin v Dolomitih in v Furlaniji; 77-123

72. Nada STOJANOVIĆ - Zdenka ŠAU: Elementi non italiani nella lingua giornalistica contemporanea - Neitalijanske prvine v italijanskem casopisnem sodobnem jeziku; 125-129

73. Fedora FERLUGA-PETRONIO: Il natale nelle lingue slave - Božið v slovanskih jezikih; $131-150$

74. Jože TOPORIŠIČ: O strukturalnem določanju besednih pomenov (ob glagolu biti) - Strukturelle Erforschung von Wortbedeutungen am Beispiel des Zeitwortes biti 'sein'; 151-167 
75. Anna BUCKETT: The limitations of the linguistic analysis of literary texts Pomanjkljivosti jezikovne razčlembe literarnih besedil; 169-182

76. Otto HIETSCH: The Mirthless world of the bilingual dictionary (A critical Look at Two German-English Examples, and a Glossary) - Neveseli svet dvojezičnega slovarja. Kritika dveh nemško-angleskih del (s slovarčkom popravkov in dostavkov); 183-218

77. Mágnus PÉTURSSON: Sprachpflege und Sprachpolitik in Island - Skrb za jezik in jezikovna politika na Islandu; 219-244

78. Janez OREŠNIK: On the Lack of Palatalisation before -end-in the Plural of Icelandic nominalised present participles such as leikandi - Odsotnost palatalizacije pred -end- $v$ množini islandskih substantiviziranih sedanjiških deležnikov kot leikandi; str. 245-259

\section{XXI, 1981}

79. Božo VODUŠEK - In memoriam

80. Božo VODUŠEK: Uber nichtonomatopoetische ikonische Synonymie; 5-46

81. Gerhard ERNST: Zum Begriff der Durchsichtigkeit in der Wortbildung K pojmu prozornosti v besedni tvorbi; $47-72$

82. Bojan ČOP: Sur l'origine des thèmes pronominaux sigmatiques des langues indoeuropéennes - $\mathrm{O}$ izviru pronominalnih sigmatskih tem v indoevropskih jezikih; 73-103

83. Kenneth SHIELDS: The Indo-european third person plural verbal suffix - Indoevropska glagolska koněnica za 3. os. pl.; 105-118

84. Richard SIRBU: L'antonymie des séries dérivatives - Antonimia seriilor derivative; 119-143

85. Fedora FERLUGA-PETRONIO: I nomi delle feste Mariane nelle lingue slave Imena Marijinih praznikov v slovanskih jezikih; 145-165

86. Anton GRAD: Starejצi grecizmi v slovenšcini (II) - Anciens grécismes en slovène; (II); 165-173

87. Dušan LUDVIK: Langobardisch Gastald -Langobardsko gastald; 175-184

88. Stojan BRAČIČ: Zu einigen Entwicklungstendenzen beim Ausdruck der Gewissheitsmodalität - O razvojnih tendencah pri izražanju gotovostne modalnosti; 185-207

89. Otto HIETSCH: Unmuffing the 'muffel'. Living Usage and Laggard Lexicalisation - Razmufliranje besede $M u f f e l$ ali zapoznelo sprejemanje žive rabe v slovarje; 209-225

90. Anna BUCKETT: On literary narratives, fictionality, and the rules of conversation - O literarni pripovedi, izmišljenosti in pravilih govora; 227-250 
91. Pavao TEKAVČIĆ: Costanza, ripetizione, regressione, unicità nell'evoluzione dell'italiano letterario - Stalnost, ponavljanje, regresija i jednokratnost $u$ razvoju talijanskog književnog jezika; 251-275

92. Mitja SKUBIC: La langue des inscriptions latines en Slovénie - Jezik latinskih napisov v Sloveniji; $277-298$

93. Jože TOPORIŠČ́; Slovenisch als Fremdsprache - Slovenšcina kot tuji jezik; 299-316

\author{
Porocila, ocene in zapisi - \\ Comptes rendus, récensions, notes
}

94. Olga MIŠESKA TOMIĆ; Generative Syntax in Theory and Practice /Milena Milojevic-Sheppard; 317-323

95. LADINIA (I-IV) /Pavao TekavčiČ/; 325-331 deležnikov kot leikandi; 245-259

\title{
XXII, 1982
}

96. Giovan Battista PELLEGRINI: Alcune osservazioni sul "retoromanzo" - Namesto povzetka: Retoromanšcina; 3-64

97. Roxana IORDACHE: Remarques sur le "ut concessif" du latin et les origines de la relative concessive - Pripombe $\mathrm{k}$ rabi lat. "ut concessivum" in izvor relativno-koncesivnega odvisnika; $65-89$

98. Pavao TEKAVČIĆ: Indirizzi linguistici attuali nel dominio istroromanzo - Suvremeni lingvisticki pravci $i$ istroromanski dijalekti; $91-125$

99. Breda CIGOJ-LEBEN: Rendement stylistique de l'ellipse du pronom sujet dans le "Thésée" d'André Gide - Stilistična učinkovitost izpusta pronominalnega subjekta v Gidovi pripovedi "Tezej"; 127-147

100. Irena LIPOVEC: Approccio ai legami preposizionali tra il verbo e il sostantivo in italiano - Predložne zveze glagola s samostalniško besedo v italijanščini; 149-169

101. Fedora FERLUGA-PETRONIO: Problemi di interferenza linguistica: su un errore di sintassi slovena degli studenti sloveni bilingui - Problemi jezikovne interference: napaka iz slovenske skladnje, značilna za slovenske dvojezične dijake; 171-189

102. Momčilo D. SAVIĆ: Aspektualnost i temporalnost u iskazivanju prošlosti i pretprošlosti u slovenskim i neslovenskim jezicima - L'aspectualité et la temporalité servant à exprimer la catégorie d'antériorité dans les langues slaves et non slaves; 191-204

103. Anton GRAD: K etimologiji slovenskega oronima NANOS - Contribution à l'étymologie de l'oronyme slovène Nanos; 205-209 
104. Jože TOPORIŠIČ: Strukturalismus in der Slovenistik - Strukturalizem v slovenistiki; 211-237

105. Václav BLAŽEK: Some Nostratian Etymologies - Nekaj nostratičnih etimologij; 239-248

106. Pierre SWIGGERS: Note comparative sur l'emploi temporel de isk - Primerjalna opazka o casovni rabi armenskega isk; $249-252$

107. Darja GLOBEVNIK: Syntaxe fonctionnelle et syntaxe générative - un rapprochement dans les années '70? - Funkcionalna sintaksa in generativna sintaksa zbližanje v sedemdesetih letih?; 253-276

\author{
Poročila, ocene in zapisi - \\ Comptes rendus, récensions, notes:
}

108. Ernst Pulgram; ITALIC, LATIN, ITALIAN 600 B.C. TO A.D. 1260, Texts and commentaries; Indogermanische Bibliothek, Erste Reihe: Lehr - und

Handbücher; Carl Winter Universitätsverlag, Heidelberg 1978, 400 pp. (Pavao Tekavčic); 277-297

109. Emidio de Felice, I nomi degli italiani. Informazioni onomastiche e linguistiche, socioculturali e religiose. Rilevamenti quantitativi dei nomi personali dagli elenchi telefonici. - SARIN - Marsilio Editori, Venezia 1982, pag. 358. (Mitja Skubic); 299-312

\title{
XXIII, 1983
}

110. Darja GLOBEVNIK: Modalités verbales du subjonctif à la lumière d'une analyse contrastive fonctionnelle dans les langues franaise et slovène Konjunktivne glagolske modalnosti v luči funkcionalne kontrastivne francoskoslovenske analize; 5-52

111. Tjasa MIKLIČ: L'opposizione italiana perfetto vs imperfetto e l'opposizione slovena dovršnost $v s$ nedovršnost nella verbalizzazione delle azioni passate Opozicija perfekt : imperfekt $\mathrm{v}$ italijanščini in slovenska dovršnost : nedovršnost za izražanje preteklosti; 53-123

112. Vladimir POGAČNIK: Structuration des suffixes quantificateurs en franais non conventionnel - Strukturiranje vrednostnih pripon v nenormirani francošcini; 125-174

113. Varja CVETKO-OREŠNIK: Zu neueren iranisch-baltoslawischen IsoglossenVorschlägen - K novejšim predlogom iransko-baltoslovanskih izoglos; 175-256

114. Jasna MAKOVEC: Zu Entwicklungstendenzen im Satzbau der deutschen Sprache der Gegenwart unter besonderer Berücksichtigung der Ausrahmung - 
K razvojnim tendencam v stavčni gradnji današnje nemščine s posebnim poudarkom na izpostavljanju; 257-305

Poročila, ocene in zapisi -

Comptes rendus, récensions, notes

115. G. V. Voronkova: Problemi fonologii, Izdatel'stvo Leningradskogo Universiteta, Leningrad, 136 S. (Magnús Pétursson); 307-311

116. Ines Loi Corvetto: L'italiano regionale di Sardegna, Fenomeni Linguistici num. 3, Bologna, Zanichelli 1983, IV + 244 pp. (Pavao Tekavčić); 313-326

117. Fonologia etrusca fonetica toscana; Il problema del sostrato, Atti della Giornata di Studi organizzata dal Grupo Archeologico Colligiano, Colle di Val d'Elsa, 4 aprile 1982; a cura di L. Agostiniani e L. Giannelli, Biblioteca dell' "Archivum Romanicum" serie II - Linguistica, vol. 39; Firenze, Leo S. Olschki Editore, 1983, pp. 5-197 (Pavao Tekavčić); 327-337

118. "Quaderni dell'Atlante Lessicale Toscano" 1 - 1983; Regione Toscana, Accademia Toscana di Scienze e Lettere "La Colombaria"; Leo S. Olschki Editore, Firenze 1983, 293 pagine (Pavao Tekavčić); 339-347

119. Keith E. Karlsson: Syntax and Affixation, The Evolution of MENTE in Latin ane Romance, Beihefte zur Zeitschrift für romanische Philologie, Band 182, M. Niemeyer Verlag, Tübingen 1981, IX + 163 pp. (Pavao Tekavčic); 349-358

120. Antonio Quilis: La concordancia gramatical en la lengua española hablada en Madrid, C. S. I. C., Madrid 1983, pags. 128 (Mitja Skubic); 359-361

\section{XXIV, 1984}

121. ANTON GRAD - In memoriam; 5-6

122. Gordana VITOROVIĆ: Bibliographie des oeuvres du prof. Anton Grad - Bibliografija del prof. Antona Grada; 7-10

123. Gustav INEICHEN: Pour une caractérisation typologique du franais - K tipološki karakterizaciji francoščine; 11-26

124. Lorenzo RENZI: La tipologia dell'ordine delle parole e le lingue romanze Tipologija besednega reda in romanski jeziki; $27-59$

125. Pierre SWIGGERS: Une étape dans la "chronogénèse" du guillaumisme:

L'architectonique du temps dans les langues classiques - Etapa v dojemanju casa v doktrini Gustava Guillauma: L'Architectonique du temps dans les langues classiques; $61-75$

126. Žarko MULJAČIĆ: Il fenomeno überdachung "tetto" , "copertura" nella sociolinguistica - Fenomen "krov" u sociolingvistici (s romanskim primjerima); 77-96 
127. Claude VINCENOT: Le phénomène de remanence, facteur d' analogie Remanenca, povzrocitelj analogije; 97-99

128. Irene VINCENOT: Variantes et figures (morphologie et rhétorique) - Variante in figure (morfologija in retorika); 101-109

129. Carlo Alberto MASTRELLI: Interazione latino-sabina: lat. domus, luma e bulumaca - Latinsko-sabinski medsebojni vplivi: lat. dumus, luma in bulumaca; 111-119

130. Roxana IORDACHE: L'infinitif dans les oeuvres de Jordanès - Infinitivul in operele lui Iordanes; $121-157$

131. Dieter MESSNER: Semi-palavras em português? - Polbesede v portugalščini?; 159-170

132. Fernando Venancio PEIXOTO DA FONSECA: Phonétique syntaxique en ancien portugais - Sintaktična fonetika v stari portugalščini; 171-176

133. Gerhard ERNST: Une contribution historique à l'acquisition du lexique par l'enfant. L'exemple de Louis XIII (*1601)à l'âge de 3 à 9 ans. - Prispevek k poznavanju otrokovega usvajanja besednjaka: primer Ludvika XIII (*1601) v starosti od treh do devetih let; 177-191

134. Vlado DRAŠKOVIĆ: Sur le sens de proximité de l'ancienne préposition $a(/ d)$ devant les noms de villes - $O$ značenju za blizinu starofrancuskog predloga $a(d)$ uz imena gradova; 193-201

135. Breda CIGOJ-LEBEN: Une traductrice d'André Gide devant le problème de la fidélité de la traduction - Razmišljanjqa prevajalke Gidovih del o vprašanju zvestobe prevoda; 203-216

136. Petar GUBERINA: Comment est conue la structure dans la méthode audiovisuelle structuro-globale (SGAV, en serbo-croate AVGS) - Zasnova strukture $\mathrm{v}$ audiovizualnistrukturno-globalni metodi; 217-227

137. Raffaele SIMONE: Nouvelles de l'Italie sur la linguistique et l'éducation Jezikoslovje in vzgoja: novosti iz Italije; 229-245

138. Mario MEDICI: Ancora sulla coordinazione di indicativo e congiuntivo nelle "Satire" dell'Ariosto - O priredni vezavi indikativa in konjunktiva v Ariostovih Satirah; 247-249

139. Jaro ŠAŠEL: H krajevnima imenoma Emona in Ljubljana - Zu den ON Emona und Ljubljana; 251-253

140. Manlio CORTELAZZO: Cinque etimologie veneziane antiche - Pet starih beneških etimologij; 255-263

141. Mario DORIA: Spigolature toponomastiche carsiche - Paberkovanja po kraških krajevnih imenih; 265-273

142. Pavle MERKU: Patronimici in -ič a Trieste nel Basso Medioevo - Iz očetnega imena izpeljani priimki na -ič v Trstu poznega Srednjega veka; 275-282

143. Emidio De FELICE: Postila; 283-285

144. Giovanni FRAU: Una inedita versione càrnica ottocentesca della Parabola del. 
figliuol prodigo - Še neizdana Prilika o izgubljenem sinu iz Karnije (XIX. stol); 287-302

145. Neva GODINI: Sulla penetrazione dei prestiti romanzi nello sloveno - O vdoru romanskih jezikovnih prvin v slovenščino; 303-313

146. Mitja SKUBIC: Romanski jezikovni vplivi v tržaški knjižni slovenščini. Jezik Borisa Pahorja - Influenze linguistiche romanze nello sloveno letterario di Trieste. La lingua di Boris Pahor; 315-334

147. Pavao TEKAVČIĆ: Le funzioni pragmalinguistiche dei croatismi nei testi rovignesi contemporanei - Pragmalingvistične funkcije kroatizama u suvremenim rovinjskim tekstovima; 335-353

148. Stanimir RAKIĆ: Glagol hteti i struktura pomoćnih i modalnih glagola u srpskohrvatskom jeziku - The verb hteti and the structure of auxiliary and modal verbs in serbocroatian: $355-368$

149. Liljana BIBOVIĆ: The structural possibilities of serbo-croatian related to the english structure adjective + prepositional sentential complement - Strukturne mogućnosti srpskohrvatskoga jezika u odnosu na englesku strukturu pridev + predloška rečenična dopuna; 369-382

150. Janez OREŚNIK: The origin of the cliticness of the west germanic definite article: the case of Beowulf - Od kod naslonskost zahodnogermanskega določnega člena - primer Beowulf: 383-389

151. Otto HIETSCH: Productive Second Elements in Nominal Compounds: The Matching of English and German - Produktivne druge sestavine imenskih kompozitov: angleško-nemške vzporednosti; 391-414

152. Stojan BRAČIČ: Zur Schichtung der gegenwärtigen deutschen Nationalsprache unter besonderer Berücksichtigung des Substandards - $O$ zvrsteh sodobnega nemškega jezika s posebnim ozirom na podstandard; $415-425$

153. Vladimir E. OREL: Studies in the Albanian vocabulary (Balkan etymologies 7691) - Doneski $k$ albanskemu besedišcu (balkanske etimologije 76-91); 427-442

154. Václav BLAŽEK: Gr. pithekos; 443-447

155. Alemko GLUHAK: Two Nostratic etymologies - Divje nostratičke etimologije; 449-453

156. Metka FURLAN: Hittite huelpi- "young, tender, fresh" and IE Č +Hulp-, $\check{C}+$ Hlup - - Hetitsko huelpi- "mlad, nežen, svež" in ide. $\check{C}+$ Hulp, С +Hlup-; 455466

157. Marko SNOJ: Indoeuropean ${ }^{+} e$ in Luwian - Refleksi indoevropskega ${ }^{+}{ }_{e} \mathrm{v}$ luvijščini: 467-476 
158. Giuseppe FRANCESCATO: A proposito del suffisso - eo- - Pripona -eo- v furlanščini; 3-17

159. Giovan Battista PELLEGRINI: Una rara voce friulana nella terminologia dei "cestai" - Redka furlanska beseda v terminologiji pletenja košev; 19-28

160. Michele METZELTIN: Il valore semantico del complemento oggetto nelle frasi goldoniane - Semantične vrednosti direktnega objekta v Goldonijevih stavkih; 2943

161. Josip JERNEJ: Osservazioni sulla pausa sintattica - Napomene o sintaktickoj pauzi; 45-52

162. Vojmir VINJA: Autour des STATUTA POLAE a. 1431. Quelques remarques et réinterprétations - Oko Statuta Pule iz g. 1431. Prijedlog za neka nova tumačenja; 53-70

163. Marius Ilie OROS: Toponymic interferences - Interferente toponomice; 71-79

164. Radu FLORA: Onomastique des V/a/laques balkaniques - et celle des Istroroumains actuels - Onomastica $\mathrm{V} / \mathrm{a} /$ lahilor balcanici si cea a istroromânilor actuali; 81-93

165. Marija BOLTA: The subject-to-subject raising rule in Slovene - Pravilo o dviganju osebka v osebek v slovenšcini; $95-110$

166. Vilko NOVAK: Ueber die Phonetik des Dialekts von Prekmurje in der Volksund Schriftsprache - $O$ fonetiki prekmurskega narečja v ljudskem in knjižnem jeziku; 111-131

167. Jože TOPORIŠIČ: Soziolinguistische Probleme der Slowenischen (Schrift) Sprache - Družbenostna vprašanja slovenskega (knjižnega) jezika; 133-156

168. Varja CVETKO OREŠNIK: Zu dem sogenannten präfixalen $a$-im Slawischen $\mathrm{K}$ domnevnemu prefiksu $a$ - v slovenščini; 157-166

169. Tine KURENT: Kozmos - arhitektura; 167-173

170. Mágnus PÉTURSSON: Phonemfluktuation im modernen Islandischen. Erster Versuch einer Beschreibung - Menjavanje dveh fonemov, kjer bi pričakovali samo enega, $v$ moderni islandšini; 175-185

171. Franco CREVATIN: Note di linguistica bawlé - Opombe k jezikoslovju bawlé; 187-191

172. Bojan ČOP: Indouralica X; 193-262

XXVI, 1986

173. G. Battista MORETTI: Per una didattica delle preposizioni completive 
nell'italiano contemporaneo - Za didaktiko dopolnilnih odvisnikov v sodobni italijanšcini; 5-57

174. Mitja SKUBIC: Interferenze linguistiche slavo-romanze: la lingua di "Novi Matajur" - Slovensko-romanski medsebojni jezikovni vplivi: jezik "Novega Matajurja"; 59-68

175. Pavao TEKAVČIĆ: Neologismi tecnici ed affini nella prosa rovignese attuale Tehnicki srodni neologizmi u suvremenoj rovinjskoj prozi; $69-82$

176. Hans GOEBL: Considérations dialectométriques sur le problème de "l'unité rétoromane (ladine)" - Pogledi dialektometrije na vprašanje "retoromanske (ladinske) enotnosti"; 83-97

177. Dieter KATTENBUSCH: Osservazioni in occasione di una visita ai croati del Molise (Italia) - Ob obisku pri Hrvatih v pokrajini Molise (Italija); 99-106

178. Fernando V. PEIXOTO FONSECA: A propos de l'influence de la langue portugaise - Leksikalni vplivi portugalక̌ine; 107-113

179. Muhamed NEZIROVIĆ: El cancionero de los romances judeo-españoles de Sarajevo de Laura Papo Bojoreta - Cancionero judovsko-španskih romanc iz Sarajeva Laure Papo-Bojorete; 115-130

180. Roxana IORDACHE: Tendances originales dans l'emploi de certains éléments du latin scientifique et de chancellerie à la basse époque, chez Claudien Mamertus - Znanstveno in administrativno izrazoslovje v pozni latinski dobi: svojskost $v$ rabi Klavdijana Mamerta; 131-147

181. Varja CVETKO-OREŠNIK: Etymologisches zu einigen slowenischen DialektWörtern - Etimološki doneski k nekaj slovenskim narečnim besedam; 149-157

182. Mágnus PÉTURSSON: Janez Orešniks Beitrag zur Erforschung der isländischen Sprache - Prispevek Janeza Orešnika k raziskavam islandక̌cine; 159-170

183. Vladimir E. OREL: Albanica parerga. Balkan etymologies 101-109 - Balkanske etimologije 101-109; 171-176

184. Peter SWIGGERS et Karl VAN DEN EYNDE: L'harmonie vocalique: remarques descriptives et théoriques - Ubranost samoglasnikov: opombe $\mathbf{k}$ opisu in teoriji; $177-180$

\author{
*** \\ Poročila, ocene in zapisi- \\ Comptes rendus, récensions, notes
}

185. Gerhard Ernst: "Gesprochenes Französisch zu Beginn des 17. Jahrhunderts". Direkte Rede in Jean Héroards "Histoire particulière de Louis XIII" (16051610), Beihefte ZRPh, Band 204, Niemeyer, Tübingen 1985; pp.623/Giuseppe Francescato/; 181-184 
186. Wolfgang U. Dressler, Morphonology: the dynamics of derivation. Ann Arbor, založba Karoma 1985; 439 strani /Janez Orešnik/; 185-192

187. Annibale Elia: Le verbe italien, Les complétives dans les phrases à un complément, Biblioteca della ricerca, Linguistica comparata diretta da Annibale Elia e Maurice Gross, vol. 1, Schena (Fasano di Puglia) - A.-G. Nizet (Parigi), 1984, 305 pp. /Pavao Tekavcic/; 193-197

188. Pierre SWIGGERS: Les conceptions linguistiques des Encyclopédistes, Etudes sur la constitution d'une théorie de la grammaire au siècle des Lumières, Sammlung Groos 21, Julius Groos Verlag - Heidelberg - Leuven University Press, Heidelberg 1984; 165 pp. /Pavao Tekavčic/; 198-201

189. "Ladinia", Sföi cultural dai Ladins dles Dolomites, numm.V. (1981) - VIII (1984), Institut Ladin "Micurà de Rü", San Martin de Tor, Piccolino (Val Badia),/Pavao Tekavčic/; 202-210

190. Estudis Gramaticals 1, amb ponències del Col.loqui Internacional de Lingüìstica Teorica i Llengües Romàniques, Working Papers in Linguistics; Universitat Autonoma de Barcelona, Departement de Filologia Hispànica, Barcelona,Bellaterra 1984, 380 pp. /Pavao Tekavčič/; 211-215

191. Novi lingvistički časopis: SOL - Lingvistički časopis, godina I, broj 1, Zagreb 1986, str. 108. Izdavač: Filozofski fakultet Zagreb, OOUR Humanističke i drustvene znanosti /Pavao Tekavcić/; 216-218

XXVII, 1987

192. Pierre SWIGGERS: Comparaison des langues et grammaire comparée. Réflexions méthodologiques - Od primerjave jezikov do primerjalne slovnice. Metodološka razmišljanja; 3-10

193. Olga KUNST-GNAMUŠ: Linguistic form between system and use - Jezikovna oblika med sistemom in rabo; 11-21

194. Stojan BRAČIČ: Zum Begriff der kommunikativen Funktion in der Linguistik $\mathrm{K}$ pojmu komunikativne funkcije v jezikoslovju; 23-32

195. Neva GODINI: Il punto su Sebastiano Krelj - O jeziku v delih Sebastiana Krelja; 33-45

196. Tatjana SREBOT-REJEC: The sound systems of English and Slovene compared: a distinctive feature analysis - Glasovna sestava anglešcine in slovenšcine ter razločevalna obeležja v obeh jezikih; 47-61

197. Momčilo D. SAVIĆ: L'aroumain entre dialecte et langue - Aromunščina - jezik ali narečje?; 63-72

198. Pavao TEKAVČIĆ: Frasi interrogative nell'istroromanzo rovignese odierno Upitne rečenice u današnjem rovinjskom istroromanskom govoru; 73-85 
199. Dieter MESSNER: A difusao de palavras portuguesas, problemas e métodos Razsirjanje portugalskih besed, problemi in metode; 87-98

200. Dora MAČEK: Relativization in Swedisch. Some contrastive aspects. Relativizacija u švedskom jeziku. Neki kontrastivni aspekti; 99-109

201. Sorin PALIGA: The Social Structure of the South-East European Societies in the Middle Ages. A Linguistic View. - Socialna struktura družb v srednjem veku. Jezikovni pogledi; 111-126

202. Magnús PETURSSON: Ist Sandhi ein Fiktives oder ein Reales Linguistiches Problem - Je Sandhi izmišljeno ali resnično jezikoslovno vprałanje?; 127-133

203. Bojan ČOP: Indouralica XII; 135-161

204. Alemko GLUHAK: Lid. srfasti - Lyd. srfasti; 163-165

Poročila, ocene in zapisi-

Comptes rendus, récensions, notes

205. Vojmir Vinja: Jadranska fauna. Etimologija i struktura naziva, I-II, Split, Logos, 1986: I vol. pp. 5-504, II vol. pp. 1-558/Pavao Tekavčić/; 167-174

206. Studi ladini in onore di Luigi Heilmann nel suo $75 \check{C} 0$ compleano, a cura di Guntram A. Plangg e Fabio Chiocchetti,"Mondo Ladino" X (1986), Institut Cultural Ladin "majon di fasheng", Vigo di Fassa, pp. 3-466 /Pavao Tekavčić/; 175179

207. Ladinia. Sföi culturâl dai Ladins dles Dolomites, IX (1985), pp. 1-260; X (1986), pp. 1-123 /Pavao Tekavčić/; 180-185

208. Stéfan Einarsson, Studies in Germanic Philology, edited by Anatoly Liberman, Helmut Buske Verlag Hamburg 1986 /Dora Maček; 186-188

209. Achile G. Lazarou: L'aroumain et ses rapports avec le grec, Institute for Balkan Studies, Thessaloniki 1986, p. 304 /Momčilo D. Savic/; 189-191

210. Anne Betten, Sprachrealismus im deutschen Drama der siebzieger Jahre. Monographien zur Sprachwissenschaft 14. Carl Winter. Universitätsverlag, Heidelberg, 412 s. /Stojan Bračč/; 192-195

\section{XXVIII, 1988}

211. Nora GALLI DE' PARATESI: Norma in linguistica e sociolinguistica e incongruenze tra norma e uso nell'italiano d'oggi - Norma v lingvistiki in sociolingvistiki ter neskladje med normo in rabo v današnji italijanščni; 3-13

212. Maria ILIESCU: La prammatica degli aggettivi dimostrativi rumeni - Pragmatica adjectivelor demonstrative în limba româna; 15-33 
213. Roxana IORDACHE: Remarques sur les raisons de la conservation de la conjonction latine si dans les langues romanes - Observatii asupra motivelor conservarii conjunctiei latine si în limbile romanice; 35-46

214. Josip JERNEJ: Considerazioni sui problemi sociolinguistici nelle regioni dell'Alpe-Adria - O jezičnoj problematici na području Alpe-Jadran; 47-48

215. Mario DORIA: Sulla storia del toponimo istriano Rabac - K zgodovini istrskega krajevnega imena Rabac; 49-51

216. Pavle MERKU: La i parassita nello sloveno triestino - Prehodni i v tržaški slovenšcini; 53-54

217. Mitja SKUBIC: L'apporto linguistico sloveno al friulano di Gorizia - Jezikovni prispevek slovenščine $\mathbf{k}$ furlanక̌čini v Gorici; 55-66

218. Pavao TEKAVČIĆ: Sintassi, semantica, pragmatica in alcuni interessanti casi di ambiguità nei testi istroromanzi moderni - Sintaksa, semantika, pragmatika u istroromanskim tekstovima: o nekim zanimljivim sluxajevima višeznačnosti; 67-74

219. Hans GOEBL: Il posto dialettometrico che spetta ai punti - AIS 338 (Adorgnano, Friuli), 398 (Dignano / Vodnjan, Istria) e 367 (Grado, Friuli) - Mesto, ki v dialektometriji pripada za AIS raziskanim točkam 338 (Adorgnano, Furlanija), 398 (Dignano / Vodnjan, Istra) in 367 (Gradež, Furlanija); 75-97

220. Sorin PALIGA: A pre-Indo-European place-name: Dalmatia - Dalmatia: predindoevropski toponim; 105-108

\author{
$* * *$ \\ Echanges de points de vue - \\ Tehtanja in mnenja
}

221. Pavao TEKAVČIĆ: L'istroromanzo in una recente pubblicazione linguistica. Aggiunte, commenti, rettifiche, risposte alla problematica istroromanza nel volume omaggio a Žarko Muljačić Romania et Slavia Adriatica - Istroromanski govori u jednoj nedavno izašloj lingvističkoj publikaciji; 111-124

222. Manlio CORTELAZZO: Postille triestine - Triestinske postile; 125-131

223. Mitja SKUBIC: Ai margini di una pubblicazione importante - Na rob pomembne publikacije: Mario Doria, Grande dizionario del dialetto triestino; 133-139

\author{
*** \\ Comptes rendus, récensions, notes - \\ Porocila, ocene, zapisi
}

224. Giovanni Frau: Dizionario toponomastico del Friuli-Venezia Giulia. Udine, Istituto per l'Enciclopedia del Friuli-Venezia Giulia, 1978 /Eric Hamp/; 141-147 
225. E. La Stella: Dizionario storico di deonomastica. Vocaboli derivati da nomi propri, con le corrispondenti forme francesi, inglesi, spagnole e tedesche, Firenze, Leo S. Olschki Editore, 1984 /Renato Gendre/; 148-152

226. Akten der Theodor Gartner-Tagung (Rätoromanisch und Rumänisch) in Vill /Innsbruck 1985, herausgegeben von G. A. Plangg und M. Iliescu, Romanica Aenipontana XIV, Innsbruck 1987 /Pavao Tekavčic/; 153-159

227. Horst Geckeler - Dieter Kattenbusch: Einführung in die italienische Sprachwissenschaft, Romanistische Arbeitshefte hrsg. von Gustav Ineichen und Bernd Kielhöfer, vol. 28, Tübingen 1987 /Pavao Tekavčič/; 160-163

228. Slovenska krajevna imena/Noms de lieux slovènes/, Cankarjeva založba, Ljubljana 1985 /Mitja Skubic/; 164-166

229. Jan Baudouin de Courtenay: Materiali per la dialettologia e l'etnografia slava meridionale ( $z a$ južnoslovansko dialektologijo in etnografijo, IV, inediti, pubblicati a cura di) pripravila za prvo objavo Liliana Spinozzi Monai, con commento folklorico di / folklorni komentar prispeval Milko Maticetov, EST Trieste / ZTT Trst 1988 /Mitja Skubic/; 167-169

\section{XXIX, 1989}

230. Bojan ČOP: Hundert Jahre eines bekannten slowenischen Sprachwissenschaftlehrs, Professor Dr. Karel Oštir - Ob stoletnici rojstva slovenskega jezikoslovca dr. Karla Oštirja; 3-11

231. Bojan ČOP: Indouralica IX; 13-56

232. Sorin PALIGA: Types of mazes - Tipuri de labirint; 57-70

233. Pavao TEKAVČIĆ: Le interiezioni (fonosimboli) nella prosa rovignese dell'antologia "Istria nobilissima " - Uzvici u rovinjskoj prozi objavljenoj u antologiji "Istria nobilissima"; 71-80

234. Zorica VUČETIĆ: Contributo allo studio della suffissazione nominale nell'italiano contemporaneo. Raffronto contrastivo - Prilog proucavanju sufiksalne tvorbe imenica u savremenom talijanskom jeziku. Kontrastivni pristup; 8199

235. Milorad ARSENIJEVIĆ: Romanske sledi v toponomastiki Vojvodine - Quelques traits romans dans la toponomastique de la Voïvodine; 101-106

236. Hildo Honório DO COUTO: $\mathrm{O}$ crioulo guineense en relaçao ao portugus e às línguas nativas - Kreolšcina v Gvineji in njen odnos do portugalšcine in do jezikov domorodcev; 107-128

237. Fernando Venâncio PEIXOTO DA FONSECA: Aspectos do vocabolário e semântica do portugus arcaico - Značilnosti besedišca in semantike stare portugalšcine; 129-136 
238. Mitja SKUBIC: L'estructuració de l'oració composta en el Tirant lo Blanc Zgradba povedi v katalonskem viteškem romanu Tirant lo Blanc; 137-145

Echanges de points de vue -

Tehtanja in mnenja

239. Pavle MERKU: Lettera al direttore - Pismo uredniku; 147

240. Pavao TEKAVČIĆ: Alcune riflessioni a proposito di una recentissima grammatica della lingua italiana - Neka razmišljanja u povodu jedne od najnovijih gramatika talijanskog jezika; $149-160$

241. Olga Mišeška Tomić: Syntax and Syntaxes: The Generative Approach to English sentence Analysis; Savremena administracija, Beograd 1987 /Marija Bolta/; 161167

242. Carla Ciseri Montemagno: Dai linguaggi alla lingua, Introduzione all'educazione linguistica nella scuola elementare, Firenze, La Nuova Italia 1987, 143 p. /Pavao Tekavčić/; 169-172

243. Eduardo Blasco Ferer: Le parlate dell' Alta Ogliastra, Analisi dialettologica. Saggio di storia linguistica e culturale, Studi di Linguistica sarda, Collana diretta da Eduardo Blasco Ferer e Heinz Jürgen Wolf, num. 1; Cagliari, Edizioni Della Torre 1988, XI + 259 pp., con 5 carte e 3 fotografie /Pavao Tekavčić/; 173-178

244. Vocabularul representativ al limbilor romanice, de Mihaela Bîrladeanu, M. Iliescu, Liliana Macarie, Ioana Nichita, Mariana Ploae-Hanganu, Marius Sala, Maria Theban, Ioana Vintila-Radulescu; coordinator Marius Sala; Universitatea Bucuresti, Institutul de Lingvistica; Editura Stiintifica si Enciclopedica, Bucuresti 1988,629 pp./Pavao Tekavčić/;179-185

Note de la rédaction-

Opomba redakcije

\section{XXX, 1990}

245. Janez OREŠNIK et alii: Introduction to the Subsequent Three Papers in the Present Volume - Uvod k naslednjim trem člankom v pričujoči številki časopisa;5 - 12

246. Frančiška TROBEVŠEK-DROBNAK: Expanded tenses in the Old English Orosius - Skladenjske spremembe. Angleški razširjeni časi; 13 - 46

247. Andrej SNEDEC: The Progress of a Syntatic Change. English - do - Support Razvoj skladenjske spremembe. Angleški glagol do; 47 - 68 
248. Karmen TERŽAN: Das Worden-passiv als syntaktische Verstärkung im Deutschen - Trpnik z worden kot skladenjska okrepitev v nemšcini; 69 - 100

249. Stojan BRAČIČ: Kommunikative Funktion der gegenwärtigen deutschen Umgangssprache, nachgewiesen an Reiseberichten aus der Presse - Komunikativna funkcija sodobnega nemškega pogovornega jezika v časopisnih potopisih; 101-150

250. Lucija ČOK-PIŠOT: Contributo alla didattica della lingua italiana come lingua seconda - Prispevek k didaktiki italijanščine kot $\mathrm{L}_{2} ; 151$ - 168

251. Jasmina MARKIČ: Sobre las perífrasis verbales en español - O glagolskih perifrazah v španščini; $169-206$

\author{
*** * \\ Comptes rendus, récensions, notes - \\ Poročila, ocene, zapisi
}

252. Andreas Harder: Laut- und Formenlehre der Mundart von Ripatransone , Kiel 1988/Pavao Tekavčić/; 207 - 210

253. Heidi Siller-Runggaldier, Grödnerische Wortbildung, Romanica Aenipontana XV, Innsbruck 1989/Pavao Tekavčić/; 211 - 217

254. Franz Rainer, I nomi di qualità nell'italiano contemporaneo, Wiener romanistische Arbeiten 16, Wien 1989/Pavao Tekavčić/; 218 - 223

255. "Ladinia" XI (1987) - XII (1988) /Pavao Tekavčić); 224 - 228

256. La langue française au XVI ${ }^{\mathrm{e}}$ siècle: usage, enseignement et approches descriptives, La Pensée linguistique 2, Louvain 1989/Vladimir Pogačnik/; 229 - 230

257. Slovenski pravopis, I. Pravila, SAZU - Državna založba Slovenije, 1990 /Mitja Skubic/; 231 - 232

258. Elena Rizzi, Italiano regionale e variazione sociale: L'italiano di Bologna, Bologna 1989/Mitja Skubic/; 233 - 234

259. Variatio linguarum. Beiträge zu Sprachvergleich und Sprachentwicklung. Festschrift zum 60. Geburtstag von Gustav Ineichen, Stuttgart 1989/Mitja Skubic/; 235 - 237

260. Studien zur romanistischen Wortgeschichte. Festschrift für Heinrich Kuen zum 90. Geburtstag, Stuttgart 1989/Mitja Skubic/; 238 - 241

261. Svend Bach og Jørgen Schmitt Jensen, Større italiensk gramatik, Munksgaard 1990/Mitja Skubic/; 242 - 244

262. Grande grammatica italiana di consultazione. A cura di Lorenzo Renzi, vol. I, Bologna 1988 /Mitja Skubic/; 245 - 254

263. Gordana VITOROVIĆ: LINGUISTICA XVI - XXX; 255 - 286 


\section{I . LINGUISTIQUE}

Problèmes, théories et méthodes - histoire de la linguistique et des langues

Problèmes généraux

Motivation du signe linguistique

80

Traduction littéraire

Comparaison des langues

192

Syntagme et système

193

Fonction communicative dans la

linguistique

194

Les langues

Théorie indo-ouralienne

indo-européennes

Analogie 127

Les langues slaves

Structuralisme

104

Le serbocroate

Méthode audiovisuelle

136

Le français

Caractérisation typologique

123

L'italien

Innovations linguistiques

91

L'istriote

Tendances linguistiques actuelles

98

Le frioulan

Dialectométrie

219

Le rhéto-roman

Classification

96

Problème de l'unité

176

L'aroumain

Langue ou dialecte?

197

Phonétique, phonologie et orthographe

Phonétique générale

Phonétique comme partie de la

linguistique

9

Fonction de l'accent

Sandhi

202

Les langues

Indouralica

indo-européennes

231, 172, 203 
Le latin

Les langues slaves

Le slovène

Le portugais

L'anglais

L'islandais

Le turc

Le louvite
Inscriptions latines en

Slovénie

92

Première palatalisation

Le premier livre slovène,

orthographe

31

Dialecte de Prekmurje

166

Les sons slovènes et les sons

anglais

196

L'i parasite

216

Phonétique syntaxique

132

Les sons slovènes et les sons

anglais

196

Quantité des voyelles

22

Quantité des consonnes et des

voyelles

36

Préaspiration des occlusives

37

Deux phonèmes au lieu d'un seul

170

L'harmonie vocalique

184

$\mathrm{Le}^{+} \boldsymbol{e}$ indo-européen

157
Les langues préindoeuropéennes

Les langues indo-

européennes

Le latin

Le slovène

Les langues romanes

Le français

L'italien
Locatif sans terminaison

62

Thèmes pronominaux sigmatiques

82

Verbe, $3^{\mathrm{e}}$ personne $\mathrm{pl}$.

83

Inscriptions en Slovénie

92

Infinitif, /lordanes/

130

Verbe, temps, aspect

111

Influences romanes, /B. Pahor/

146

Verbe, temps passés - la langue

de la presse

58

Phrase, typologie

123

Verbe, temps, aspect 
L'istriote

Les parlers istroromans

L'islandais

Substantif, adjectif, adverbe - flexion 7 .

Verbe, pronom - flexion

23

Participe présent

78

Le hittite

Substantif en uar - flexion

16

Verbe $d a-a b-h i$

15

Verbes causatifs

L'arménien

$-I S K-$

106

\section{Syntaxe}

Syntaxe générale

Le latin

Les langues slaves

Le slovène

Le serbocroate

Les langues romanes

Le français
Syntaxe transformationnelle pronom et problème de référence

6

Syntaxe fonctionnelle, syntaxe générative 107

Ut concessivum $\quad 97$

Verbe, temps, aspect

102,111

Substantif, génitif en -no-,

-to-

Verbe, subjonctif

"Subject -to- subject raising rule" 165

Influences romanes (B. Pahor) 146

Verbe hteti 148

Adjectif + complément prépositionnel

equivalent de l'anglais

149

Relativisation en suédois, aspect

contrastif

200

Verbe, temps passés

27

Ordre des mots, typologie

124

Conjonction latine "si"

213

Ellipse, anaphore en 10

Verbe, subjonctif $\quad 60$

Modalité verbale du subjonctif $\quad 110$

Phrase, typologie 
L'italien

Rection et accord 3

Coordination et accord $\quad 41$

Le groupe prépositionnel $\quad 100$

Verbe, temps, aspect 111

Indicatif et subjonctif, Arioste $\quad 138$

Phrase, pause 161

Proposition subordonnée $\quad 173$

Le vénitien Complément d'objet,/Goldoni/ $\quad 160$

$\begin{array}{lll}\text { L'istriote } & 198\end{array}$

$\begin{array}{lll}\text { Rovinj } & \text { Exemples de polysémie } & 218\end{array}$

L'espagnol Périphrases verbales 251

Le catalan Phrase, le roman "Tirant lo Blanc" 238

Phrases subordonnées, l'infinitif 61

Le roumain

Adjectifs démonstratifs 212

$\begin{array}{lll}\text { Les langues germaniques } & \text { Relativisation } & 200\end{array}$

L'anglais

Article défini, Beowulf $\quad 150$

L'expansion des temps composés $\quad 245,246$

Verbe -do- 247

L'allemand

"Ausrahmung"

2,114

Verbe, indicatif

88

Verbe, passif avec worden $\quad 248$

\section{Etymologie}

Les langues préindo-

Toponyme Dalmatia

européennes

Les langues indo-européennes Lexèmes, noq ${ }^{u}$

Le grec

Lexèmes pour labyrinthe

Hom. hypodra 50

Gr. pithekos

Kozmos "architecture"

Le latin

Dumus, lumae, bulumaca

Emona

Les langues slaves

Božič "Noël"

73

Noms des fêtes de Marie

85 
Siromah 13

bok, pozoj, pozòj (slov., hrv.kaj.) 32

Les langues balto- slaves

Isoglosses

Le slovène

Toponymes, Carst

52,141

Rašpor, Voglajna,

55,69

Nanos, Emona

lo3,

Patronymes, Trieste

Quelques mots dialectaux:

s'kuša, präpa'lica, píonta

181

Le serbocroate

Les toponymes Rabac, Beram

55,215

Les langues romanes

L'italien

Toponomastique de la Voïvodine

235

Les latinismes ecclésiastiques:

visibilio, strabiliare et

trasecolare

54

Le vénitien

(en) Istrie

25

anciennes étymologies: beretín

far gionda / giondar, polorbo

saran, vieto

Le langobarde

gastald

87

Le hongrois

Lexème labda

8

Les langues balkaniques

Ban, čoban, župan

201

L'albanais

gjuhë, me, palcë, vrap, akull,

bashkë, berr, bli

153,183

Les langues

gam, bag ou pak

105,155

nostratiques

L'etrusque

miror "zrcalo"

17

Nombres

18

Le hittite

huelpi

156

L'iranien

isoglosses

113

Le lydien

srfasti

204

Les langues africaines

bawle

171

\section{Lexique et sémantique}

Lexique général

Transparence des dérivés

81

Les langues classiques 
Le latin

Les languès slaves

Le slovène

Les langues romanes

Le français

L'italien

Le frioulan

Le portugais
Latinité médiévale en Yougoslavie 24

Vitruvio: symetria

51

Noms des poissons - Statut Polae

Q. 1431

162

Basse époque, Claudien Mamertus $\quad 180$

Homonymie

20

Božič "Noël" 73

Noms des fêtes de Marie $\quad 85$

Anciens grécismes

53,86

Verbe biti

74

L'a préfixal

168

Romanismes, Krelj

195

Antonymie, séries dérivatives

84

Langue non conventionnelle -

suffixes quantificateurs

112

Ellipse, anaphore en

10

Modalité verbale, Flaubert

40

Métaphore et métonomie

128

Lexique enfantin

133

Prépositions $a(d)$ devant les

toponymes

134

Tanto

59

La langue de la presse - éléments

non italiens

72

Eléments vénitiens, Trieste

222

Suffixes nominaux, aspect

contrastif

234

Noms des plantes

71

Suffixe -eo-

158

Cestai

159

Emprunts du croate

147

Néologismes, Rovinj

175

Prose, interjections

232

Eléments des mots composés

131

Lexèmes portugais dans d'autres langues 
Le roumain

L'istroroumain

L'anglais

Le hittite

L'arménien
Antonymie

57

Onomastique des V/a/ laques

balkaniques

164

La langue parlée dans les

dictionnaires

76

Mots composés

151

MUFFEL

89

Inventaire de Mannini

35

-ISK-

106

Interférences linguistiques

Les langues slaves

Le slovène

Le serbocroate

L'italien

Le frioulan

Le roumain

Le créole

(Guinée)

Le grec

Les langues slaves
Emprunts des langues romanes

145

Influences romanes, Novi Matajur

174

Mélanges des langues et dialectes, pour J. Baudouin de Courtenay

29

Les dialectes slovènes au contact avec le frioulan, gérondif présent

Bilinguisme dans la syntaxe

5

Influences romanes, B. Pahor

101

Bilinguisme

146

Slavismes dans l'oeuvre de

P. Aretino

30

Eléments frioulans, Gorizia

217

Bilinguisme

26

Toponymie, Banat

163

Le portugais + langues indigènes

\section{Sociolinguistique}

Hittites et Grecs

Territoire Alpe-Adria 
Le slovène

Langue littéraire

167

Le croate

Les langues romanes

L'italien

Les langues germaniques

L'allemand

Les Croates à Molise (Italie)

177

Tetto, copertura (= Überdachung) 126

Norme et emploi

211

Territoire Alpe-Adria

Le rôle du substandard

214

152

\section{Instruments de travail}

Bibliographies

Grammaires

Dictionnaires

Mélanges

Article monographique

Karel Oštir

Milan Grošelj

Božo Vodušek

Anton Grad
Quinze ans de Linguistique $\quad 14$

Milan Grošelj $\quad 48$

Anton Grad 122

Grammatica della lingua italiana

di P. Agazzi, A. Fallica e A.

Menegoi

241

M. Doria : Grande dizionario del

dialetto triestino

223

Piccoli vocabolari enciclopedici

11

Romania e Slavia Adriatica, omaggio

a Žarko Muljačić

221

Contribution de J. Orešnik à la

recherche de l'islandais

182

LINGUISTES slovènes 


\section{CIVILISATION, LITTERATURE ET STYLISTIQUE}

grecque

latine

slovène

française

italienne

frioulane

judéo-espagnole

anglaise

allemande

islandaise

hittite

indienne

archéologie
Semonides

64

Inscriptions de Poetovio

65

Aristofan, Plutos, Basino

de Parma

66

Cicero et Martin Luther King

49

(le slovène) comme langue

étrangère

93

Le style d'André Gide

39,99

Linguistique et l'éducation

137

Contribution à la didactique

250

"Prilika o izgubljenem sinu iz

Karnije"

144

Romances de Laura Papo Bojorete

Bosnie (Sarajevo)

179

Cicero et Martin Luther King

49

L'analyse linguistique des

textes littéraires

75

Récit littéraire, aspect

pragmatique

90

La langue des écoliers, évolution

linguistique

21,38

Fonctions communicatives -

langue moderne des reportages

249

La politique linguistique en

Islande

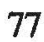

"Festival hitrosti" (CTH 626)

4

Notes philologiques aux vers de

Védas

Ajdovski gradec 
ARSENIJEVIĆ, Milorad 235

BENEDIK, Martin 48

BIBOVIĆ, Liljana 149

BLAŽEK, Vaclav 105, 154

BOLTA, Marija 165,241

BRAČIČ, Stojan $\quad 88,152,194,210,249$

BUCKETT, Anna $\quad 75,90$

CIGOJ-LEBEN, Breda $\quad 39,99,135$

CORTELAZZO, Manlio $\quad 30,140,222$

CREPAJAC, Ljiljana 70

CREVATIN, Franco $\quad 25,33,55,171$

CVETKO-OREŠNIK Varja $34,63,113,168,181$

ČOK, Lucija 250

ČOP, Bojan $\quad 1,16,82,172,203,230,231$

DE COUTO, Hildo Honorio 236

DE FELICE, Emidio 143

DERBYSHIRE, William W. 20

DORIA, Mario $\quad 52,141,215$

DRAŠKOVIĆ, Vlado 134

ERNST, Gerhard $\quad 81,133$

FERLUGA-PETRONIO, Fedora 73, 85, 101

FLORA, Radu 164

FRANCESCATO, Giuseppe $\quad$ 158, 185

FRAU, Giovanni 144

FURLAN, Metka 156

GALLI DE' PARATESI, Nora 211 
GANTAR, Kajetan 47

GENDRE, Renato 225

GLOBEVNIK-ŽOORGA, Darja $\quad 40,60,107,110$

GLUHAK, Alemko 17, 18, 32, 155, 204

GODINI, Neva $\quad$ 145, 195

GOEBL, Hans 176,219

GRAD, Anton $\quad 53,86,103,121$

GROŠELJ, Milan 24,45

GUBERINA, Petar 136

HAMP, Eric 224

HEUSINGER, Siegfried 2, 21, 38

HIETSCH, Otto $76,89,151$

ILIESCU, Maria 212

INEICHEN, Gustav 123

IORDACHE, Roxana $\quad 97,130,180,213$

JERNEJ, Josip $\quad 3,161,214$

KATTENBUSCH, Dieter 177

KOŠAK, Silvin $\quad 4,35,67$

KUNST-GNAMUŠ, Olga 193

KURENT, Tine $\quad 51,169$

LENČEK, Rado 5,29

LIPOVEC, Irena 100

LUDVIK, Dušan 87

MAČEK, Dora 200, 208

MAKOVEC, Jasna 114

MARKIČ, Jasmina $\quad 251$

MASTRELLI, Carlo Alberto $\quad 54,129$

MEDICI, Mario 138

MERKU, Pavle 142, 216, 239

MESSNER, Dieter $\quad 131,199$ 
METZELTIN, Michele 160

MIHEVC-GABROVEC, Erika 46

MIKLIČ, Tjaša 111

MILOJEVIĆ,-SHEPPARD, Milena $\quad 6,94$

MORETTI, G. Battista 173

MULJAČIČ, Žarko $\quad 42,126$

NEZIROVIĆ, Muhamed 179

NOVAK, Vilko 31, 166

OREL, Vladimir E. $\quad 153,183$

OREŠNIK, Janez $\quad 7,23,37,78,150,186,245$

OROS, Marius Ilie 163

PALIGA, Sorin $\quad 201,220,232$

PEIXOTO DA FONSECA, Fernando Venancio $\quad$ 132, 178, 237

PELLEGRINI, Giovan Battista $\quad 8,44,71,96,159$

PETRU, Peter 68

PETRUŠEVSKI, M. D. 50

PETURSSON, Magnus $9,22,36,43,77,115,170,182,202$

POGAČNIK, Vladimir 10,112

POPOVIĆ, Milica 11

POVŠIĆ, Boleslav S. 49

RAKIĆ, Stanimir 148

RANČIGAJ, Željka 59

RENZI, Lorenzo 124

SAVIĆ, Momčilo D. 26, 58, 102, 197, 209

SCHMALSTIEG, William R. 12,15

SCIELDS, Kenneth $\quad 62,83$

SIMONE, Raffaele 137

SIMONITI, Primož 66

SIRBU, Richard $\quad 57,84$

SIRONIĆ, Milivoj 64 
SKUBIC, Mitja $\quad 27,61,92,109,120,146,174,217,223,228$, $229,237,257,258,259,260,261,262$

SNEDEC, Andrej 247

SNOJ, Marko 157

SREBOT-REJC, Tatjana 196

SWIGGERS, Pierre $106,125,184,192$

ŠAŠEL, Jaro 69,139

ŠAŠEL-KOS, Marjeta 65

ŠAU, Zdenka 72

SIVIC-DULAR, Alenka 13

TEKAVČIĆ, Pavao $\quad 28,41,56,91,95,98,108,116,117,118$, $119,147,175,187,188,189,190,191,198$, $205,206,207,218,221,226,227,233,240$, $242,243,244,252,253,254,255$

TERŽAN, Karmen 248

TOLSTOJ, Vladimir Iljic 19

TOPORIŠIČ, Jože $\quad 74,93,104,167$

TROBEVŠEK-DROBNAK, Meta 246

VINCENOT, Claude 127

VINCENOT, Irène 128

VITOROVIĆ, Gordana $\quad 14,122$

VODUŠEK, Božo 79, 80

VUČETIĆ, Zorica 234 